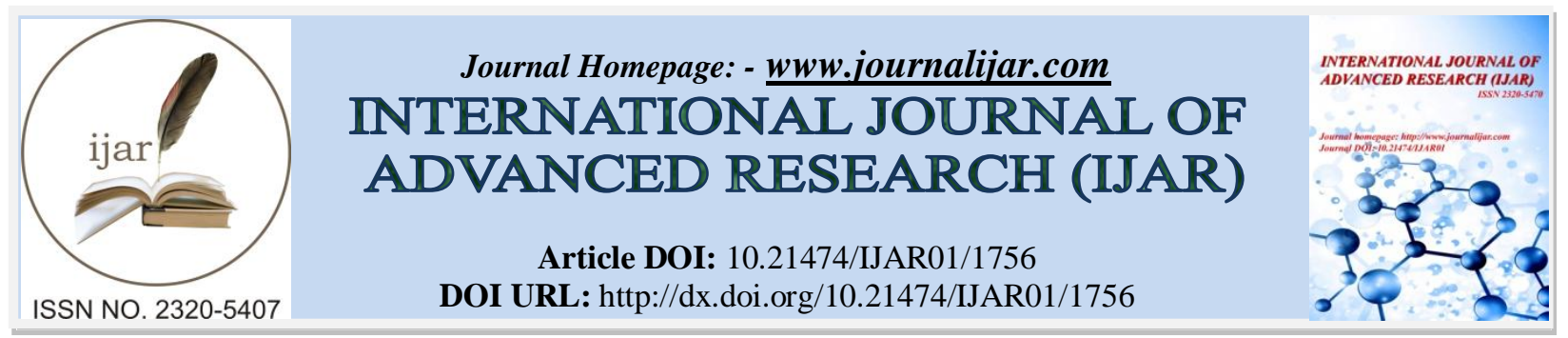

RESEARCH ARTICLE

\title{
PRINT MEDIA ROLE IN COMMUNICATING THE KEY CRISIS EVENTS OF NATURAL DISASTERS IN UGANDA.
}

Caroline Nabuzale $^{1}$, Dr Hellen Mberia ${ }^{2}$ and Prof Gregory .S. Namusonge ${ }^{3}$.

1. $\mathrm{PhD}$ in Mass communication candidate, Jomo Kenyatta University of Agriculture and technology Kigali campus Rwanda.

2. Dean school of communication and development studies, Jomo Kenyatta University of Agriculture and technology, main campus Nairobi Kenya.

3. Lecturer Jomo Kenyatta University of Agriculture and technology, main campus Nairobi Kenya.

\section{Manuscript Info}

Manuscript History

Received: 12 August 2016

Final Accepted: 22 September 2016

Published: October 2016

Key words:-

Framing.

Newspapers.

Disaster.

\section{Abstract}

The study sought to evaluate the effectiveness of print media on communicating the key crisis events of natural disasters in Uganda. Moreover, the study employed a qualitative research designs. The study was investigated using 3 newspaper archives. Whilst, the findings of the study indicate that the print media's factual coverage for natural disasters helps to build trust for the newspaper in the public sphere and therefore promotes crisis communication because the medium is the message. Moreover, very appealing messages help to enhance crisis communication . whilst inability for the print media to amplify the risk for natural calamities hinders disasters prevention and recovery for the affected people. Notably, government should ensure that the media regulatory bodies monitor the coverage of issues of national concerned or public interest. They should be given priority in the media because disasters have a great negative impact on the health of citizens.

Copy Right, IJAR, 2016,. All rights reserved.

\section{Introduction:-}

The climate change adaptation communication plan and media engagement strategy in Uganda is monitored by Ministry of information and Uganda communication commission Kimumwe (2014).Despite the sheer size of this institutional communication framework, vast sections of Ugandans continue to be affected by natural disasters. On average, disasters affect more than 200,000 Ugandans every year Kabwegere (2010). From a media framing perspective, communities' vulnerability could be caused by poor and biased framing of the crisis communication content by the media (Shoemaker\& Reese, 1996; Holladay, 2009). Moreover, poor and biased framing of content is due to ideology of those in power in society, lack of follow up and accountability on the communication structures, media routines and socialization, attitudes, instructing, adjusting and internalizing information Reese et al (1996). To the best of author's knowledge, similar investigations have not been carried out in Uganda. Moreover effectiveness of crisis communication by media has been a major focus of empirical research in developed countries. However, the insights are yet to be revealed in the context of Uganda.

Corresponding Author:- Caroline Nabuzale. 
The objective of the study was to evaluate the effectiveness of print media on communicating the key crisis events of natural disasters in Uganda.

\section{Research Question:-}

How do news papers cover the key crisis events of the natural disasters in Uganda?

\section{The Normative Theories of the Press:-}

The study employed the Normative theory of the press, the theories were used to asses journalism as a profession and describe the role of the press in democratic societies as cited by Holbert (2013) in (Christians et al 2009).This theory posits that the press should focus on values and be objective in reporting, rather than detailing specific processes of influence .These theories apportion the ideal functions of the press, what the press should do Holbert (2013). The media has a lot of functions to do in society which include; informing, education, sensitizing and reach the grass roots in development related activities from the government. The Normative theories of the press were used to inform this study about the role of print media in the crisis communication that's media as a link between government and the grass roots helps to promote development in democratic society where there are free markets of ideas from both government/crisis managers and the affected population in natural disasters in Uganda (Semiu et al, 2012\&Hollady, 2009).

\section{Media role in natural disaster coverage:-}

The media plays a much broader role in both pre- and post-disaster reporting; this is more evident in the longer term view of the media as it relates to disasters usually in the post-disaster reporting. According to Wilkins (2004) in Rausch (2011), there are five phases of disaster reporting that can be viewed on their proximity to the event itself: warning, impact, immediate post impact, recovery and mitigation. Moreover, media coverage develops a narrative which defines the meaning of the disaster as well as identifying any contributing or mitigating factors that may have contributed to or influenced the nature or scale of the disaster but which are identified clearly post-event rather than pre-disaster (Rausch , 2011).

Whilst print media plays a number of roles that include informing and educating that forms an interaction platform in social organizations. This is a close link to natural disasters recovery. During the reporting of the major events of the crisis as they unfold, the media helps to interpret these issues that lead to reading of these events. Therefore the roles of the print media are vital in natural disasters. Some of the roles performed by print media include social utility role; dissemination of information to various population categories in different geographical locations that leads to civic engagement of the rural people through information availability, the media enables social experience in heterogeneous communities. The media provides a social platform for people (Miles \& Morse, 2006).

Furthermore, over-reporting of post-event disaster risks leads to general fear and anxiety among the affected people and can cause health problems. There is also a persistent pre-disaster risk communication profile and accordant policy making. The press also modifies post-disaster media discourse to minimize rationality in the reporting, replacing it with myth and in the process allows the central government to propagate and carry out international public relations campaign to show case their political ideologies (Holladay ,2009; Miles \& Morse , 2007) .

\section{Methodology:-}

The study employed a qualitative approach .Secondary data was obtained using document analysis of 3 news papers achieves because there were available records about crises and have the highest number of readership compared to other news papers that's ; The New vision newspaper, The Daily Monitor newspaper and the Red Pepper newspaper Alowo (2010) which was used to make data valid .Document reviews of news media content frames for the events surrounding natural disasters in Uganda was conducted to establish a general awareness of recurring themes and issues as Ickowitz ( 2012). Moreover, the archived newspapers were used to retrieve the content which was analyzed. The researcher found a set of terms that shared a similar semantic meaning of the three stages applied to categorize the content. The unit of content analysis was studied to collect all necessary data to answer the research questions. The units of analysis were newspapers released during the period spanning from the 2012 to June 2016; pre-crisis stage to the post-crisis stage (Morgan et al, 1998).

\section{Results and Discussions:-}

The findings of the study indicate that, from the New vision newspaper, the major themes reported about natural disasters were environmental oriented, while framing for the media reports were very critical on the victims of the 
natural disasters, moreover the media was very sincere and factual in the representation of disaster events .Furthermore the media used discourse through making the disasters a headliner and also used a photo caption to emphasize the catastrophe. Whilst the findings from the Red Pepper newspaper indicate that the main themes which were highlighted were environmental oriented. Moreover the framing for the crisis information was favorable, while the media reports indicate that, the crisis information was factual and sincere. Furthermore the media used a photo caption to describe the events of natural disasters and dramatized language which was very appealing to the audiences with a sense of humor. Furthermore the findings from the Daily monitor indicate that, the main themes discussed about natural disasters in this newspaper were environmental oriented. Moreover the media reports were neutral in nature, they did not take biasness. Notably, the media reports in this newspaper indicate that the framing for content was factual. Moreover the study indicates that the Daily monitor used a lot of photo captions and the natural disasters were made headlines in the news.

Moreover there is need for newspaper to exercise independence and objectivity in reporting natural disasters events, which amounts to effective crisis communication. Whilst poor and biased media framing of the crisis communication content is influenced by ideology of those in power in society, media routines and socialization, attitudes, instructing, adjusting and internalizing information Reese at al (1996). Furthermore, there is need to maintain vivid description of the events, because the targeted audiences were able to receive the crisis communication. Moreover people seek media to gratify their needs which include; entertainment and diversion, relationships (Para-social) and construction for identity McQuail (2010). Whilst disasters reveal socially constructed issues which already existed before the crisis; for instance weaknesses in leadership, the social systems of the community which are rarely visible in routine life (Fothergill et al, 2004).

Furthermore, empirical studies indicate that media is a very powerful weapon for empowering communities up to grassroots levels. Through interaction and portrayal of attitudes, therefore interweaving media into crisis communication is paramount in conveying instructions and warnings to the targeted audiences, refuting inaccurate rumors, reassuring the public, soliciting assistance from the public and helping in the response effort during crisis times Lang et al (2001). Therefore there is need for media houses to maintain good media coverage for disasters through civic engagement, vivid descriptions and use of photo captions if possible and let disasters to set the agenda ,this leads to effective reporting through social responsibility and hence communication.

\section{Conclusion: recommendations, summary:-}

The print media's factual coverage for disasters helps to build trust for the newspaper in the public sphere and therefore promotes crisis communication because the medium is the message. Moreover very appealing messages help to enhance crisis communication . whilst inability for the print media to amplify the risk for natural calamities hinders disasters prevention and recovery for the affected people. Therefore there is need for the media to maintain facts so as to minimize harm or further complications related to health and the other risks, panic and confusion. Notably, in crisis management, the most relevant themes which require immediate address are health related because this involves the endangered lives of the affected people. There is need for the media to deal with issues like what happened, where was it, when did it occur and why did it happen and how did it come about so that the stakeholders can do something to mitigate further crises of the similar nature. Moreover there is need for newspapers to exercise independence and objectivity in reporting natural disasters events, which amounts to effective crisis communication. Furthermore, there is need to maintain vivid description of the events, because the targeted audiences are able to receive the crisis communication.

Notably government should ensure that the media regulatory bodies monitor the coverage of issues of national concerned or public interest. They should be given priority in the media because disasters have a great negative impact on the health of the citizens. Moreover there is need for crisis managers to monitor the media reports issued to the public through purchasing the newspapers themselves and ensuring that the media has covered the events as agreed. Whilst there is need for the crisis managers to keep in touch with the media through events and press conferences so as to provide the necessary information for media coverage because the media has a lot of influence on the public sphere. It cultivates meanings to it's audiences through interpretation of events during and after disasters.

Furthermore, there is need to maintain vivid description of the events, because the targeted audiences were able to receive the crisis communication. Moreover people seek media to gratify their needs which include; entertainment and diversion, relationships (Para-social) and construction for identity. These factors help to promote crisis 
communication. Therefore there is need for media houses to maintain good media coverage for disasters through civic engagement, vivid descriptions and use of photo captions if possible and let disasters to set the agenda ,this leads to effective reporting through social responsibility and hence communication.

Therefore the print media should demonstrate their control over the crisis situation by responding quickly, accurately, and uniformly. The public should be considered in crisis communication strategies. Primary information sources should be from within the communities to avoid the risk of undermining crisis management. Moreover, the media should be more effective in communication and vigilant.

\section{References:-}

1. Abeokuta. B. F (2013).Advanced theories of mass communication, international journal of management science and humanities, vol 1 No 1.

2. Al-hassan. S, Andani. A \& Malik. A.A, (2011) .The Role of Community Radio in

3. Livelihood Improvement; The Case of Simli Radio, The journal of field action: field actions science reports, vol 5

4. Alowo, Maryian (2010). News in the Ugandan Press: The Case of the New Vision. Unpublished master's thesis, School of Humanities, Education and Social Sciences, Örebro University

5. Bello Semiu . B, Aminat.A, \& Folarin.J (2012). Unethical Practices among Journalists and the Nigerian Public Sphere. Online Journal of Communication and Media Technologies Volume: 2 - Issue: 4 -

6. Bolarse. R \& Kavuma. M (2012). country case study, bbc.co.uk/mediaaction/pdf/Uganda.Acessed on 21/September 2015

7. Corbin. J \& Straus .A (2006). Grounded theory research: Procedures, Canons and Evaluation, Qualitative Health Research journal, vol. 16 No. 4 547-559

8. Denzin, N. K \& Lincoln .Y ( 2005) .The Handbook of Qualitative Research, Inc; 3rd edition ISBN10:0761927573, books.google.com〉SocialScience>Research 23 September 2015

9. Holbert,L, R( 2013). Developing a normative approach to political satire: an empirical perspective. International Journal of Communication VOL 7 305-323

10. Holladay, J, S (2009). Crisis communication Strategies in the Media Coverage of Chemical Accidents. Journal of public relations research (Impact Factor: 1.02), Vol 21(2): 208-217

11. Ickowitz, T, D (2012). Emergency Text Messaging Systems and Higher Education Campuses: Expanding Crisis Communication Theories and Best Practices, University of Tennessee - Knoxvill

12. Kabwegere .T (2010) . The national policy for disaster preparedness and management: directorate of relief disaster preparedness and refugees office of the prime minister, http://www.preventionweb.net/files/21032_ugandanationalpolicyfordisasterprep.pdf Accessed on 23 September 2015

13. Kwakwa. P.A ( 2012). Individual Preference for Radio Stations in The Eastern Region of Ghana, journal of communication and media technologies, Vol 2

14. Kimumwe. P (2015) . The state of Uganda journalists' safety, security and professionalism.

15. https://hrnjuganda.org/. Accessed on 23 September 2015

16. Kitutu K. M. G (2010).Landslide occurrences in the hilly areas Of Bududa district in Eastern Uganda and their Causes. http://mak.ac.ug/documents/Makfiles/theses/Kitutu_Kimone_Mary_Gorret.pdf

17. Accessed on 23 September 2015

18. Kituyi .Z.N (2007) .Conflict Management, Sustainable Peace and Development: The Mbale 1995/96 Conflict (Uganda), http://wrap.warwick.ac.uk/view/year/2007.html Accessed on 23 September 2015

19. Mojaye.E.M \& Lamidi. I. K (2015). The role of community media in building democratic values in Nigeria.European journal of research and reflection in arts and humanities, vol3, NO 1

20. Rausch S.A (2011). The Regional Newspaper in Post-Disaster Coverage: Trends and Frames of the Great East Japan Disaster, Keio Communication Review No. 35

21. Subramanian .A\& Jha.K.S (2010). Report on the status of Disaster Risk Reduction in Sub-Saharan Africa. The International Bank for Reconstruction and Development/ The World Bank 1818 H Street, N.W. Washington, D.C. 20433, U.S.A

22. Shoemaker.J.P \& Reese. D. S (1996) .Mediating the message: theories of influences on mass media content, 2nd edition. p. cm. Bibliographical references and index. ISBN 0-8013-1251-5 https://journalism.utexas.edu/sites/journalism.utexas.edu/files/attachments/reese/mediating-the-message.pdf Accessed on 24 September 2015 